\title{
Pedestrian Bridge Simulation Using Wasted Tire Rubber with Two Boundary Systems
}

\author{
Eleyan Issa Jamal Issa ${ }^{1}$, Alrosan Sora ${ }^{2}$, Sallam Shoroq ${ }^{1} \&$ Hammad Safaa ${ }^{1}$ \\ ${ }^{1}$ Department of Civil Engineering, Amman Arab University, Amman, Jordan. \\ ${ }^{2}$ Researcher, Private Sector, Amman, Jordan. \\ Correspondence: Eleyan Issa Jamal Issa, Department of Civil Engineering, Amman Arab University, Amman, \\ Jordan. E-mail: issaeleyan@yahoo.com \& Dr.issaeleyan@aau.edu.jo
}

Received: September 27, 2019

Accepted: October 18, 2019

Online Published: October 22, 2019

doi:10.5539/mas.v13n11p89

URL: https://doi.org/10.5539/mas.v13n11p89

\begin{abstract}
The development of pedestrian bridge construction, ranging as it does, from a simple tree trunk, laid a cross a stream, through to today's spectacular three-dimensional support structures. Limited resources, environmental concerns, economic feasibility as well as the cost; are very important factors. These factors in addition to safety, durability and aesthetics should be considered in the design and construction processes for Pedestrian bridges. Therefore, it's important to look for alternative construction materials that verify most of these factors. Waste rubber tire is a material that can be used to develop new forms of Pedestrian bridges. In this research, a simple experiment was conducted to simulate the real pedestrian bridge using waste rubber tire. The use of waste rubber tire showed positive results as a structural member in carrying loads. Consequently, it can sustain the safe passing of pedestrians. In addition, the use of fixed boundary conditions has reduced the central deflection of the bridge span to about fifty percent.
\end{abstract}

Keywords: boundaries conditions, bridge deflection, footbridges, pedestrian bridge, waste rubber tire

\section{Introduction}

Wood, stone and steel used to most common materials in building bridges; but since the 19th century, steel and concrete have a predominated the area of bridge building. Generally, the building of bridges is funded by governments to serve the public, therefore, the main goals of the designing and building of the bridges need to be prepared, planned and executed to highest efficiency to be safe, economically feasible. Increasing performance while reducing the use of expensive material through using economically and tested materials will lead to a well designed long live and safe bridges that serve public interests for years to come.

In recent decades, the worldwide growth of the automobile industry and the increasing use of cars as the main means of transport have tremendously boosted tires production. It is estimated that every year the globe is faced with over one billion $1 * 10^{9}$ waste tires worldwide. This massive number of waste tires has grown dramatically to reach such threatening numbers making it environmentally catastrophic issue that must be dealt with globally (Abhijitsinh, et al., 2015). Burying wasted tires is the most common practice used by many countries causing catastrophic environmental threats to ecology, because burial grounds will become useless with the reduction of its service life.

Commonly, Tires of all types are made from a chemically improved rubber and are designed to last for long period of time. Therefore, the issue of reusing them need to prioritize urgently, to protect the environment and to find the most economical effective way to reuse waste tires to have green effect both in energy and the environment in away by reversing the negative effects to positive ones (Hilal, A.A., 2011; ASTM C39, 2009). Scientific researchers around the world whom are aware of this environmental disaster had worked for long time to figure different scenarios of recycling waste tires while being aware in the same time of the massive numbers of tires introduced yearly, some solution were to produce black carbon by burning the waste tires, which still a harmful action that effect the environment due to the black exhausted residue particles that is the result of the burned tires (Abhijitsinh, et al., 2015; ASTM, C., 2011). these solutions are technically feasible, while in the same time they produce huge amounts of waste that endanger the environment through damaging the eco system. 
While the use of scrap tires in civil engineering applications is subject to the ASTM D 6270 standard (ASTM C78, 2009), as according to the structural nature, chemical structure in addition to physical properties of waste tires, lead to the beginning of testing the use of recycled rubber as a modifying material for asphalt (ASTM, 2008).

This Paper aimed to use and study a new material which is Wasted Tire Rubber (WTR) as a construction material as a structural member and deflection in two boundary conditions.

\section{Literature Review}

One of the Rubber mechanical characteristics is reversible deformation ability when subjected mechanical forces loads. Therefore, scientists had worked hard to determine the rubber types used in tires so they categories each the best uses for each type of rubber resulting in favorable results according to the industrial end usage status (Hernandez-Olivares et al., 2009; Kaloush et al., 2005). The most important for them was the physical characteristics the dynamic impact loading was that mostly noticed which is affected by the tire Elasticity structure, this led to increase testing on the mechanical, physical and chemical properties, fatigue and tension of the wasted tires by many scientists. Kimal., (2005); Khanet al., (2017) and Nakajimaet al., (2002) test results showed a change in the rubber behavior when compressed leading to increase in the contact area where a friction effect, which lead to reduce friction by using water or lubricants (Saintier al., 2006).

While literature includes several studies examining several methods of using recycled waste tires as an additive for construction material, there was a lack of studies on using recycled waste tires as a construction material.

Parmar et al. (2015) and Siringi al., (2013) investigated the alternate of fine mixture to scale back value of structure and reduce setting pollution. Completely different combos of crumb rubber with ancient fine mixture were evaluated supported workability were conducted in step with Indian Standards. The study recognized that the multiplied in proportion of Crumb Rubber in Concrete reduces the workability of concrete. will increase of Crumb rubber proportion in concrete it makes additional economical if we have a tendency to take into account it to purpose of setting protection.

Hilal et al. (2011) and Sridharan al. (2013) studied the practicableness of mistreatment crumb rubber (the product of shredding used rubber tires) as a partial sand replacement in foamed concrete, and investigated the impact of it on some properties of foamed concrete like, density, water absorption, compressive strength, strength, flexural strength and impact resistance, the results showed:

1. A partial sand Replacement in foamed concrete by crumb tires rubber ends up in cut back the density of the ultimate product, due to the particular gravity of rubber used was but it of sand.

2. Water absorption (\%) will increase with increasing of crumb rubber of tires content.

3. Decreasing in rubberized foamed concrete strength (compressive, tensile, flexural, and impact) with the increasing of crumb rubber of tires content within the mixture was continuously detected.

Kaloush et al. (2004) and Szurgott al. (2012) examined the Properties of Crumb Rubber Concrete mistreatment completely different laboratory tests, the tests showed:

1. The compressive strength small because the rubber content enhanced.

2. The high CRC rubber content combine (tennis court) had a flexural strength of virtually fiftieth but the management mix. However, the CRC combine had additional plasticity and comparable toughness values to the management mix.

3. The constant of thermal enlargement check results indicated that the CRC mixes were additional proof against thermal changes.

4. altogether failure tests, the CRC specimens stayed intact (did not shatter) indicating that the rubber particles is also engrossing forces acting upon it. Such behavior is also helpful for a structure that needs sensible impact resistance properties.

5. due to the long-run performance of those mixes weren't better-known within the field, particularly for pavement sections, the employment of such mixes was counseled in places wherever high strength of concrete wasn't as necessary (e.g. sidewalks).

Khan et al. (2017) and Thomas and Gupta (2016) analyzed the effect of addition of crumb rubber on the various properties of concrete. The crumb rubber was used as replacement over aggregates in the concrete mix. Crumb rubber was prepared from the scraps of tires. Aggregates were replaced by 5\%,10\% 15\% crumb rubber. The rubberized concrete was tested for slump and compression strength. It was found that the slump of rubberized 
concrete increases first but as the amount of rubber was increased the slump starts decreasing. It was observed that initial compression strength of rubberized concrete reduced significantly but the final strength was found to be more than that of ordinary concrete.

Siringi et al. (2013) and Thomas et al. (2016) analyzed The performance of concrete with crumb rubber through comparison to traditional concrete in terms of compressive strength (ASTM C39; Way and Evans, 2006), enduringness (ASTM C78 and ASTM C496; Yung et al., 2013; Zine et al., 2011), failure patterns, energy absorption throughout loading, and workability. The results show that up to fifteen exploit fine aggregates is replaced with associate degree equal volume of crumb rubber with a small improvement of the concrete workability. The crumb rubber improved the compressive strength by over five the concerns. The cacophonic enduringness slashed with a rise within the amount of crumb rubber, and therefore the modulus of rupture was slashed by a mean of twelve the concerns. However, hyperbolic strain at failure, smart energy absorption, improved modulus of toughness, and malleability were determined in rubberized concrete.

\section{Testing Program}

Material: during all the test stages, the following materials have been used to simulate the following actual bridge component.
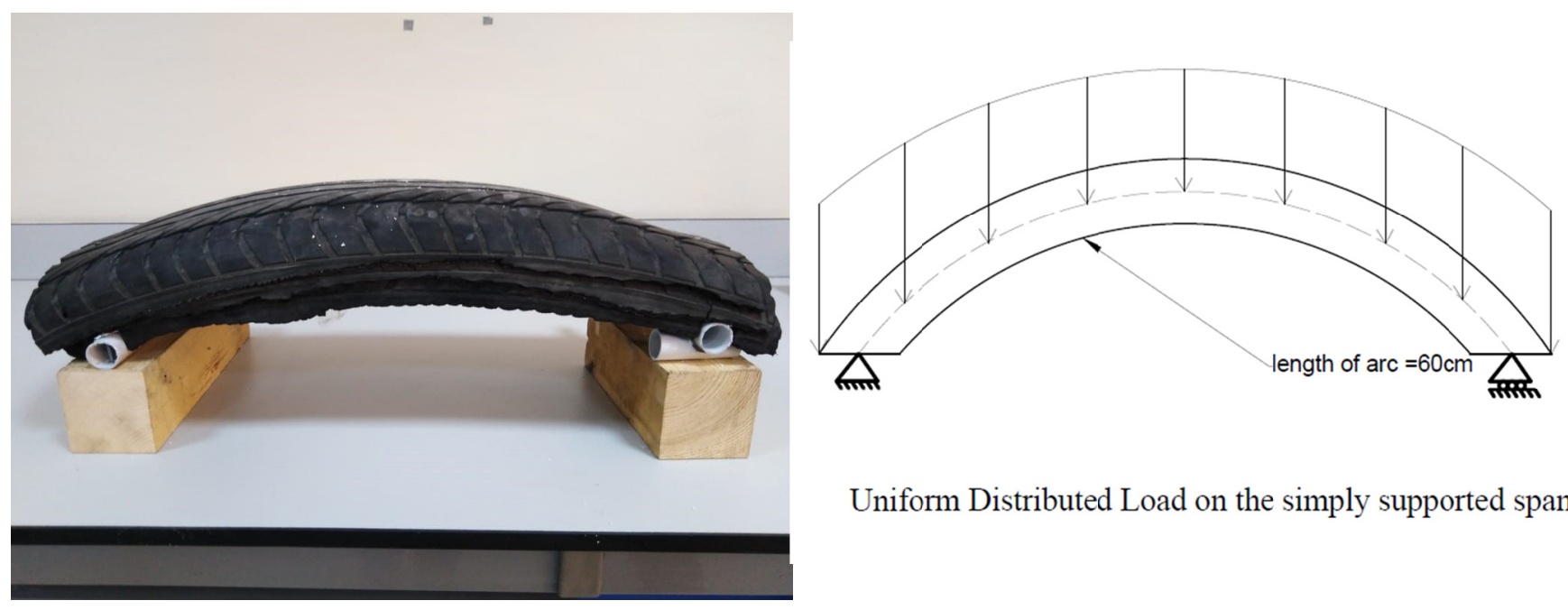

Uniform Distributed Load on the simply supported span

Figure 1. Simulation of simply supports 
Table 1. Composition of Tire Rubber and Mechanical Properties of Tire Rubber

\begin{tabular}{cccc}
\hline \multicolumn{4}{c}{ Composition of Tire Rubber } \\
\hline $\boldsymbol{S .} \boldsymbol{N}$ & INGEDIENTS & WT. (in $K G)$ & $P H R$ \\
\hline $\mathbf{1}$ & RENACIT-7 & 0.020 & 0.060 \\
$\mathbf{2}$ & NATURAL RUBBER (RMA) & 15.000 & 50.000 \\
$\mathbf{3}$ & SYNTHETIC RUBBER (SBR) & 20.000 & 68.750 \\
$\mathbf{4}$ & CARBON BLACK (HAF) & 24.000 & 70.000 \\
$\mathbf{5}$ & ZINC OXIDE & 1.750 & 5.000 \\
$\mathbf{6}$ & STEARIC ACID & 0.700 & 2.000 \\
$\mathbf{7}$ & H.S./TQ & 0.525 & 1.500 \\
$\mathbf{8}$ & 4020 NA & 0.175 & 0.500 \\
$\mathbf{9}$ & WOOD ROSIN & 0.700 & 2.000 \\
$\mathbf{1 0}$ & RUBBER PROCESSING OIL (RPO) & 3.500 & 10.000 \\
$\mathbf{1 1}$ & P.WAX & 0.525 & 1.500 \\
$\mathbf{1 2}$ & SULPHUR & 0.770 & 2.200 \\
$\mathbf{1 3}$ & CBS & 0.525 & 1.500 \\
$\mathbf{1 4}$ & PVI & 0.040 & 0.120 \\
$\mathbf{1 5}$ & TMTD & 0.070 & 0.200 \\
& Total & 68.300 & \\
\hline & Mechanical Properties of Tire Rubber \\
\hline $\mathbf{S . N}$ & Test & UNIT & READING \\
& & KG/CM2 & 145.5 \\
$\mathbf{1}$ & TENSILE STRENGTH & 40 \\
$\mathbf{2}$ & TEAR STRENGTH & 68 \\
$\mathbf{4}$ & HARDNESS & KG/CM2 & 1.2 \\
$\mathbf{5}$ & DENSITY OF COMPOUND & 400 \\
$\mathbf{6}$ & MODULAS@300\% & 110 \\
\hline
\end{tabular}

\section{Testing Procedure}

Three layers of wasted tire rubber were placed on top of each other each layer has a $60 \mathrm{~cm}$ length and $30 \mathrm{~cm}$ in width, and as a simulation of the reality the three layers were fastened by an adhesive material to make them as a single layer, the system simulates two different supports simply support(S.S) and fixed supports(F.S), for S.S is a statically determined structure, therefor one end was laid over a free PVC Pipe of a $4 \mathrm{~cm}$ in diameter simulating a roller support to allow the translation in horizontal direction and resist vertical loads, the other end was laid to a fixed PVC pipe having a diameter of $4 \mathrm{~cm}$ and length $35 \mathrm{~cm}$ simulating a pinned support to resist vertical and horizontal loads, as shown in figure No.1 While for F.S both ends were bolted as shown in figure No.2 

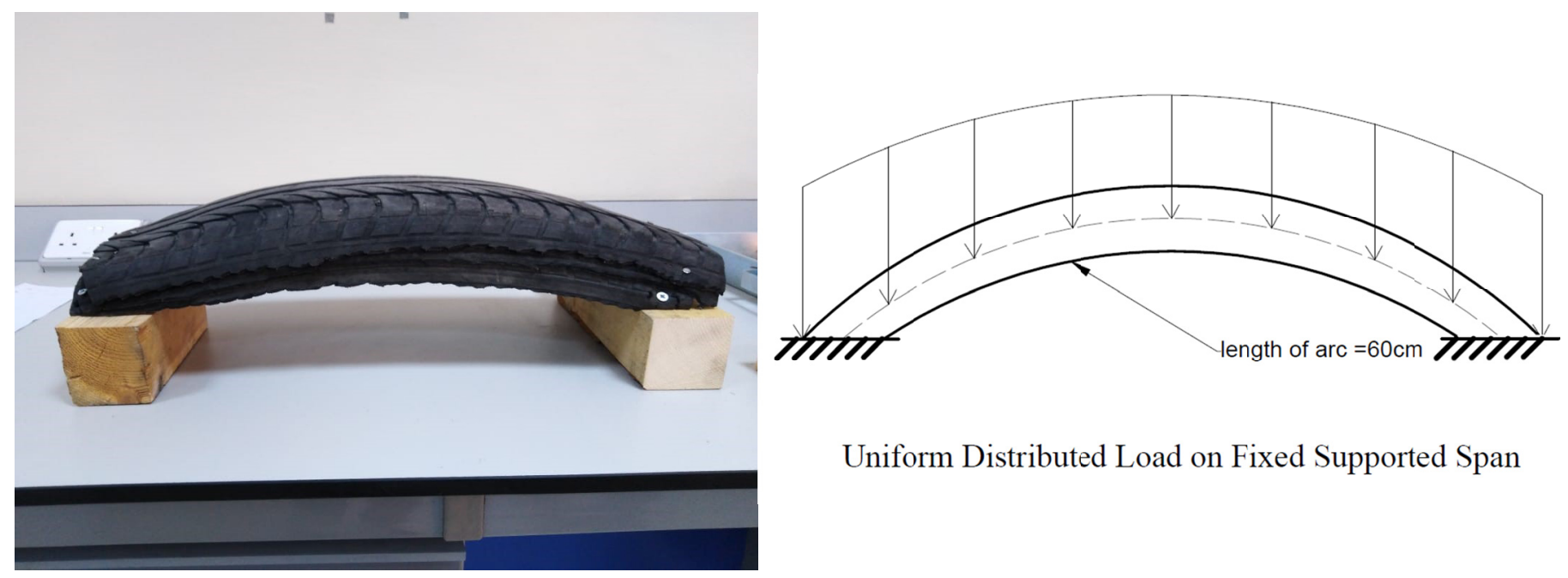

Figure 2. Fixed supports simulation

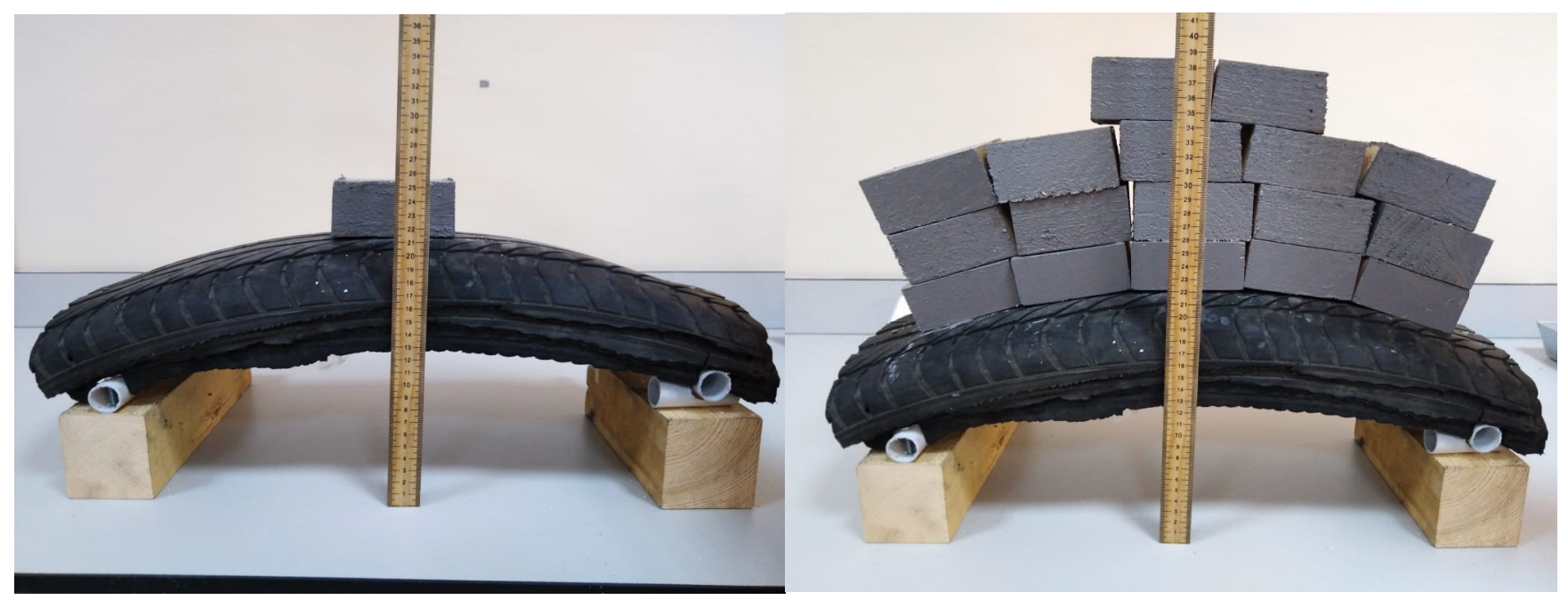

Figure 3. Incremental Loading continued on the simply supported span

A segmental loading was applied uniformly for the whole span length as shown in figure No.3 for Simply supported waste tire.

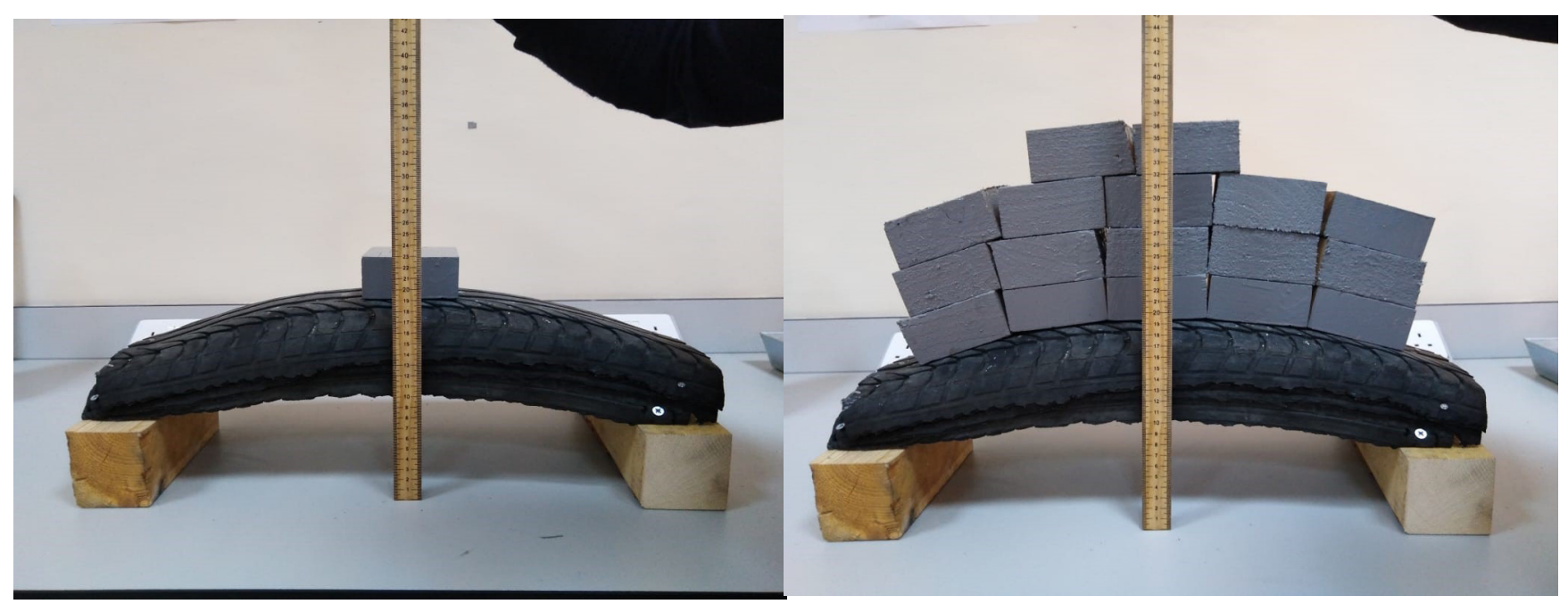

Figure 4. Incremental Loading continued on the Fixed supported span 
In addition, figure 4 for Fixed supported waste tires. While deflection was measured by a wooden ruler as shown in previous figures. The central deflection for both S.S and F.s were tabulated in table 2.

Table 2. Deflection measurements for simply and fixed supports

\begin{tabular}{cccc}
\hline \multirow{2}{*}{$\boldsymbol{N o}}$. & Weight & Simply supported Def. & Fixed supported Def. \\
\cline { 2 - 4 } & $\boldsymbol{( K \boldsymbol { g } )}$ & $(\mathbf{c m})$ & $(\mathbf{c m})$ \\
\hline 1 & 0 & 0.00 & 0.00 \\
2 & 3.4 & 0.00 & 0.00 \\
3 & 6.8 & 0.38 & 0.18 \\
4 & 10.2 & 0.65 & 0.32 \\
5 & 13.6 & 0.93 & 0.46 \\
6 & 17 & 1.20 & 0.60 \\
7 & 20.4 & 1.44 & 0.70 \\
8 & 23.8 & 1.78 & 0.87 \\
9 & 27.2 & 2.05 & 1.02 \\
10 & 30.6 & 2.43 & 1.22 \\
11 & 34 & 2.60 & 1.30 \\
12 & 37.4 & 2.71 & 1.35 \\
13 & 40.8 & 2.82 & 1.43 \\
14 & 44.2 & 2.90 & 1.50 \\
15 & 47.6 & 3.30 & 1.68 \\
16 & 51 & 3.39 & 1.70 \\
17 & 55 & 3.50 & 1.75 \\
\hline
\end{tabular}

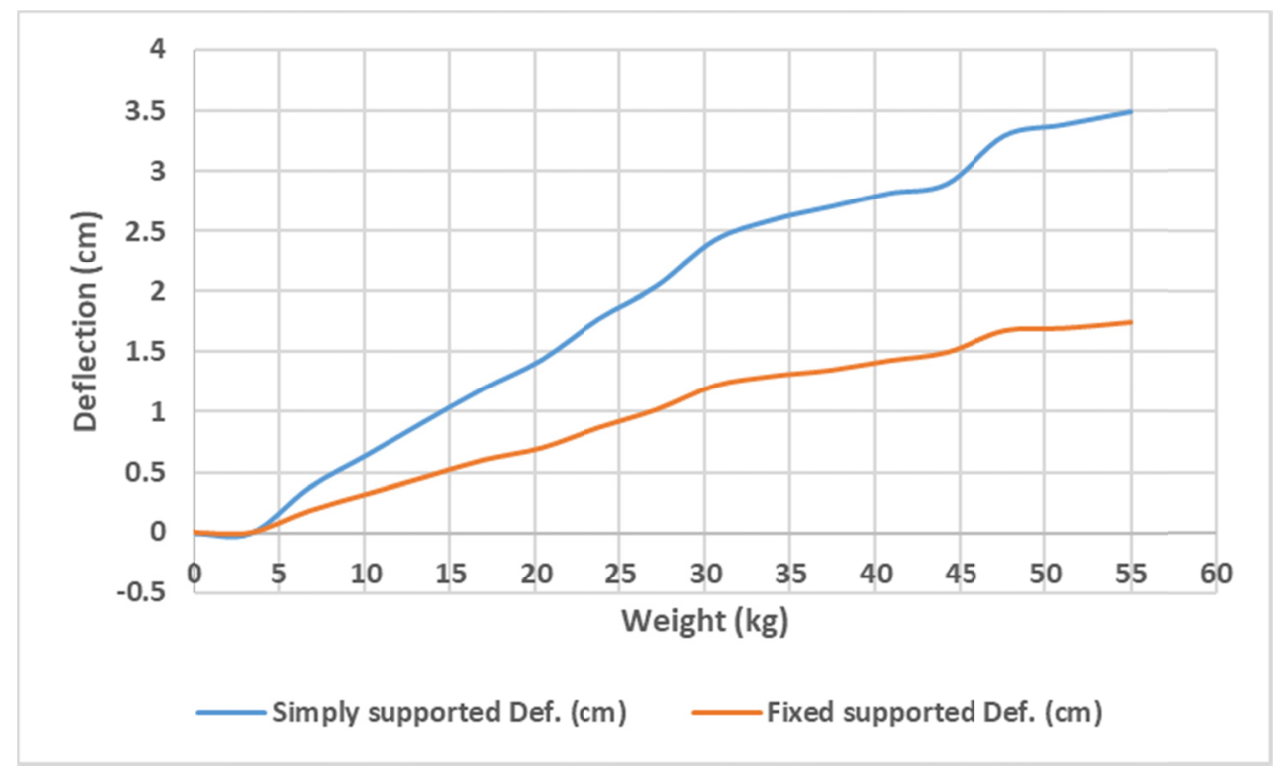

Figure 5. The magnitude and the mode of deflection

Graph in Figure 5 shows increase of the magnitude and the mode of deflection with the increase of loading during all the test stages- for both of the Fixed and the simply supported waste tire rubber.

\section{Discussion}

A footbridge (or a pedestrian bridge) is one of the road crossing facilities for pedestrians. It can be considered as the safest and the most efficient way for pedestrians. Pedestrian bridges are often created to permit pedestrians to 
cross water, valley, or railways in areas where there are no close roads. They are also located across busy highway to allow pedestrians cross safely without disabling traffic.

In this research, the span of Pedestrian bridge is 2-m wide $\mathrm{x}$ 6-m long and has a surface area of about 12 square meters. Assuming one person occupies a space of 0.25 square meter, then the maximum capacity of this pedestrian bridge is equal to 48 people at one time. If the average person's weight is assumed to be $75 \mathrm{~kg}$, then the weight limit on the bridge span is $3,600 \mathrm{~kg}$ which is equal to $55 \mathrm{~kg}$ on a waste rubber tire specimen. The weight limit on the waste rubber tire specimen was found after performing several calculations to simulate it with the weight limit on a real bridge.

Both simply supported and fixed ends tire specimens with a uniformly distributed load showed the expected deflections of both simply supported and fixed bridge span subjected to the pedestrian loads. The use of two types of boundary conditions explained the effect of the supports type selection on the reduction of unfavorite deflections in real bridges and the final result proved this effect.

Furthermore, the durability and strength of rubber tire components contributed to reduce the central deflection under the applied loads. In addition, as we know that the Tire Bead Bundles (TBB) are large mono-filament steel cords that are wound together and compounded of high strength, low flexibility rubber, to form a cable or ribbon-type configuration provides puncture resistance as well as help the tire stay flat. Therefore, TBB played an important role in the deflection reduction.

\section{Conclusions}

The following results were observed in this study:

1) The waste rubber tire is a good construction material for the Pedestrian bridge. It can sustain the safe passing of pedestrians. The construction process of structural bridge using this material will achieve the required aim of constructing a safe, functional, durable, economical and aesthetic bridge. In addition, it has an importance in solving the global environmental problem by helping dumping sites in recycling tons of automobiles or trucks scrap tires by disposing them properly and safely, instead of dumping and disposing scrap tires improperly and burn them illegally.

2) The use of fixed boundary condition for the both ends of Pedestrian bridge rather than the simply supported ends will reduce the central deflection of the bridge span to about fifty percent.

\section{References}

Abhijitsinh Parmar., Chahil Joshi, Aditi Parmar \& Urvish Patel. (2015). Use of Crumb Rubber as a Partial Replacement of Fine Aggregate in Conventional Concrete, Proceeding of 3rd Afro - Asian International Conference on Science. Engineering \& Technology, AAICSET-2015, ISBN: 9-780993-909238.

ASTM. (2009). C39: Standard Test Method for Compressive Strength of Cylindrical Concrete Specimens, Annual Book of ASTM Standards. ASTM International, West Conshohocken, PA,2009.

ASTM. (2008). Standard practice for use of scrap tires in civil engineering applications. West Conshohocken. PA: American Society for Testing and Materials.

ASTM, C. (2011). Standard test method for splitting tensile strength of cylindrical concrete specimens. C496/C496M-11.

ASTM (2009). C78: Standard Test Method for Flexural Strength of Concrete (Using Simple Beam with Third-Point Loading). Annual Book of ASTM Standards, ASTM International, West Conshohocken, PA.

Hernandez-Olivares, F., Barluenga, G., Bollati, M. \& Witoszek, B. (2002). Static and dynamic behaviour of recycled tyre rubber-filled concrete. Cement and concrete research, 32(10), 1587-1596. https://doi.org/10.1016/S0008-8846(02)00833-5

Hilal, A.A. (2011). Effect of crumb tyres rubber on some properties of foamed concrete. Anbar Journal for Engineering Sciences, 4(2), 1-17.

Kaloush, K.E., Way, G.B. \& Zhu, H. (2005). Properties of crumb rubber concrete. Transportation Research Record, 1914(1), 8-14. https://doi.org/10.1177/0361198105191400102

Khan, M.M., Sharma, A. \& Panchal, S. (2017). USE OF CRUMB RUBBER AS REPLACEMENT OVER AGGREGATE IN CONCRETE. Rubber as Replacement over Aggregate in Concrete. International Journal of Civil Engineering and Technology, 8(2), 2017, 148-152. 
Kim, J.H. \& Jeong, H.Y. (2005). A study on the material properties and fatigue life of natural rubber with different carbon blacks. International journal of fatigue, 27(3), 263-272. https://doi.org/10.1016/j.ijfatigue.2004.07.002

Nakajima, Y. \& Takahashi, F. (2002). Increase of frictional force of rubber block by uniform contact pressure distribution and its application to tire. Rubber chemistry and technology, 75(4), 589-604. https://doi.org/10.5254/1.3544986

Saintier, N., Cailletaud, G. \& Piques, R. (2006). Multiaxial fatigue life prediction for a natural rubber. International Journal of Fatigue, 28(5-6), 530-539. https://doi.org/10.1016/j.ijfatigue.2005.05.011

Siringi, G.M., Abolmaali, A. \& Aswath, P.B. (2013). Properties of concrete with crumb rubber replacing fine aggregates (Sand). Advances in Civil Engineering Materials, 2(1), 218-232.https://doi.org/10.1520/ACEM20120044

Sridharan K. \& Sivaramakrishnan R. (2013). Compressive and shear analysis of rubber block under large strain. American Journal of Applied Sciences, 10(7), 681-687. https://doi.org/10.3844/ajassp.2013.681.687

Szurgott, P., Gotowicki, P. \& Niezgoda, T. (2012). Numerical analysis of a shaped rail pad under selected static load. Journal of KONES, 19, 407-414. https://doi.org/10.5604/12314005.1137462

Thomas, B.S. \& Gupta, R.C. (2016). Properties of high strength concrete containing scrap tire rubber. Journal of Cleaner Production, 113, 86-92. https://doi.org/10.1016/j.jclepro.2015.11.019

Thomas, B.S., Gupta, R.C. \& Panicker, V.J. (2016). Recycling of waste tire rubber as aggregate in concrete: durability-related performance. Journal of Cleaner Production, 112, 504-513. https://doi.org/10.1016/j.jclepro.2015.08.046

Way, G. \& Evans, R. (2006). Rubberised bitumen in road construction. The Waste \& Resources Action Programme: Banbury, UK.

Yung, W.H., Yung, L.C. \& Hua, L.H. (2013). A study of the durability properties of waste tire rubber applied to self-compacting concrete. Construction and Building Materials, 41, 665-672. https://doi.org/10.1016/j.conbuildmat.2012.11.019

Zine, A., Benseddiq, N. \& Abdelaziz, M.N. (2011). Rubber fatigue life under multiaxial loading: Numerical and experimental investigations. International Journal of Fatigue, 33(10), 1360-1368. https://doi.org/10.1016/j.jffatigue.2011.05.005

\section{Copyrights}

Copyright for this article is retained by the author(s), with first publication rights granted to the journal.

This is an open-access article distributed under the terms and conditions of the Creative Commons Attribution license (http://creativecommons.org/licenses/by/4.0/). 